\title{
Lixo eletrônico: discutindo possibilidades de descarte consciente
}

Christian Roberto de Farias Guilherme

christianrfarias@gmail.com

https://orcid.org/0000-0003-1623-6811

Universidade Tecnológica Federat do

Paraná (UTFPR), Curitiba, Paraná, Brasil

\section{Gabriel Filipe Evaristo}

evaristo@alunos.utfpr.edu.br

http://orcid.org/0000-0003-2621-2856

http://orcid.org/0000-0003-2621-2856

Paraná (UTFPR), Curitiba, Paraná, Brasil

Fabiana Roberta Gonçalves e

Silva Hussein

fabianah@utfpr.edu.br

http://orcid.org/0000-0001-9961-7083

Universidade Tecnológica Federal do

Paraná (UTFPR), Curitiba, Paraná, Brasil

Fabiana Paulett

fpauletti@utfpr.edu.br

http://orcid.org/0000-0001-5896-5110

Universidade Tecnológica Federal do

Paraná (UTFPR), Curitiba, Paraná, Brasi
RESUMO

O fácil acesso a informação decorrente do uso da tecnologia nos proporciona uma variedade de benefícios que facilitam nosso dia a dia, como, por exemplo, os aparelhos eletrônicos de comunicação, que tornaram-se essenciais para tarefas como o controle de contas bancárias e até mesmo para fins de entretenimento. No entanto, devemos nos atentar aos cuidados necessários quanto ao descarte de resíduos eletrônicos, tal que, o constante avanço tecnológico tem resultado na escassez dos recursos naturais, sendo então um ponto muito negativo para o meio ambiente. Diante disso, o objetivo deste trabalho é o desenvolvimento de uma proposta direcionada ao ensino médio a partir de conceitos de Química, Geografia, Artes e Português, visando a sensibilização crítica dos estudantes. Atualmente, existe uma necessidade de uma abordagem interdisciplinar nas escolas a fim de promover um ensino que priorize e valorize a formação dos sujeitos mediante a integração dos diversos conceitos presentes nas disciplinas escolares. Contudo, isso não depende somente do trabalho conjunto entre determinadas disciplinas, mas também da valorização da realidade e contexto em que os estudantes estão inseridos. O projeto foi resultado da união de dois outros projetos, ambos foram desenvolvidos na disciplina de Projetos Interdisciplinares Integradores Como Componente Curricular 1 e na parte dois da disciplina como resultado avaliativo iremos aplicá-lo, entretanto, está em desenvolvimento em um colégio localizado na região de Curitiba, no estado do Paraná, direcionado a duas turmas do segundo ano do ensino médio. Obtivemos o apoio até o momento de professores das disciplinas de Química, Português, direção escolar e da Pedagoga responsável pelo ano em que será aplicado o trabalho. Em relação ao lixo eletrônico que deve ser descartado corretamente, estamos pesquisando alguma empresa que fique responsável por essa coleta, no entanto, caso não haja nenhuma disposta a auxiliar, iremos conscientizar os estudantes a descartar os resíduos no local em que compraram, ou em coletas especiais administradas pela prefeitura de Curitiba. Para cada abordagem disciplinar, sugerimos conceitos a serem desenvolvidos. Na disciplina de Química, os conteúdos de inorgânica dissolução de metais pesados - podem ser trabalhados com o auxílio de softwares computacionais, podendo os alunos representar os compostos utilizando como, por exemplo, ChemSketch, Avogadro, Chemoffice, além do conceito relacionado à eletroquímica associado ao descarte de pilhas. No que tange a Geografia, sugerimos a pesquisa de temas sobre globalização e consumismo induzidos pelos avanços tecnológicos, além da discussão dos problemas ambientais decorrentes do consumo de recursos naturais. $\mathrm{Na}$ disciplina de Artes, sugerimos a elaboração de matérias de divulgação e de conscientização quanto à destinação correta de lixo eletrônico. Já em Português, a sugestão é a escrita de uma redação dissertativa argumentativa a respeito da compreensão dos estudantes em torno de toda a proposta interdisciplinar que vivenciaram durante o projeto. A temática trabalhada dessa maneira contribui com a formação crítica e social dos estudantes, através de uma sequência de cunho interdisciplinar e contextualizado, uma vez que a mesma promove impactos positivos diante de um trabalho conjunto entre diferentes áreas de atuação, o que converge com os ensejos educacionais contemporâneos.

PALAVRAS-CHAVE: Interdisciplinaridade. Ensino. Softwares computacionais. Contextualização. 